\title{
Investigation of the Causes of Premature Failure of the Suspension and Brake System of Buses "Volgabus»
}

\author{
A. V. Popov ${ }^{1}$, G. A. Chernova ${ }^{1, *}, M . V$. Velikanova $^{1}$ and N. S. Khvan ${ }^{1}$ \\ ${ }^{1}$ Volzhsky Polytechnic Institute (branch) of FSBEI of Higher Education Volgograd State Technical \\ University,Volzhsky, Russia
}

\begin{abstract}
The article gives a performance measurement ofthe suspension and brake system of buses "Volgabus-5270GH" on the basis of bus removals with different mileage values. Scheduled maintenance and repair system implies the elimination of buses removals and repair works between MO1 (MO - Maintenance Operations) and MO2. The authors have analysed malfunctions in the suspensionandbrake system. Based on many researches, it has been established that the resource of components and parts of the vehicles in kilometers of run, under proper operation, obeys the law of normal distribution.It has been determined that premature buses removals are also possible under condition of high-quality manufacturing and timely performance of maintenance with the influence of operating factors of the route network of the townVolzhsky. The analysis of bus driving modes on the main routes and their possible connection with the suspensionand brake systemfailures has been carried out. Recommendations are given to improve the performance of the buses.
\end{abstract}

\section{Introduction}

During the operation of the buses "Volgabus-5270GH", a significant number of breakdowns with faulty suspension and brake systems were recorded. During the warranty period, all malfunctions were eliminated by the manufacturer. After the expiry of the warranty, the breakdowns occurred between MO1 and MO 2, which is not in accordance with regulations and bus operating experience, and it also leads to additional costs. Therefore, it is necessary to find out possible causes of malfunctions. In the framework of this objective, it is required to examine the nature of faults in the suspension and brake systems, influence of certain factors on them, in particular the driving conditions of buses on the routes. A survey of bus modes on the main routes in Volzhsky was carried out.

The purpose of the research is to estimate performance of suspension and brake systems of the buses "Volgabus-5270GH", taking into account certain factors, in particular, bus modes.

*Corresponding author: galina_vat@mail.ru 


\section{Determining the Quantitative Performance Characteristics of the Suspension and Brake System of Buses}

\subsection{Analysis of breakdowns with brake and suspension repairs}

The municipal bus depot MUE "Volzhskaya №1732 bus depot" of the city of Volzhsky operates buses "Volgabus-5270GH" (CityRhythm-10 GLE) manufactured by Volgabus Volzhsky (a division of Bakulin Motors Group).The company received the 50 methanepowered buses in November 2017 as part of the environmental Programme of the Russian Federation. The buses are used on urban routes №1, №2u and №14.

From 2018 to 2020, there were recorded 339 breakdowns with brake system malfunctions and 261 breakdowns with suspension malfunctions. During the warranty period from 2017 until 2019 Volgabus Volzhsky carried out repairs. After the end of the warranty period, repairs and maintenance are carried out in the repair area ofthe municipal bus depot MUE "Volzhskaya №1732 bus depot". The mileage before maintenance is 10,000 $\mathrm{km}$ before MO 1 and 20,000 km before MO 2.

To estimate performance of the suspension and brake systems of buses "Volgabus$5270 \mathrm{GH}$ " an analysis of breakdowns at the municipal bus depot MUE "Volzhskaya №1732 bus depot” for the given period was carried out (Tables 1 and 2). [1,2]

Table 1. Nature of brake system malfunction

\begin{tabular}{|c|l|c|}
\hline $\begin{array}{c}\text { № } \\
\Pi / \Pi\end{array}$ & \multicolumn{1}{|c|}{ Nature of brake system malfunction } & $\begin{array}{c}\text { The number of } \\
\text { the removals }\end{array}$ \\
\hline 1 & Faulty anti-lock system & 15 \\
\hline 2 & The parking brake does not work & 6 \\
\hline 3 & Rear left wheel cannot be released ( it is heated) & 71 \\
\hline 4 & Rear right wheel cannot be released ( it is heated) & 82 \\
\hline 5 & Wheel does not release & 1 \\
\hline 6 & Left brake drum is jammed & 6 \\
\hline 7 & Right brake drum is jammed & 11 \\
\hline 8 & Front left wheel cannot be released & 6 \\
\hline 9 & Front right wheel cannot be released & 6 \\
\hline 10 & Front left wheel cannot be released ( it is heated) & 15 \\
\hline 11 & Front right wheel cannot be released ( it is heated) & 38 \\
\hline 12 & No brake release & 6 \\
\hline 13 & Brakes do not operate & 5 \\
\hline 14 & Front left brake is not functioning & 6 \\
\hline 15 & Front right brake is not functioning & 7 \\
\hline 16 & Rear left brake is not functioning & 3 \\
\hline 17 & Rear right brake is not functioning & 5 \\
\hline 18 & Brake actuator adjustment & 16 \\
\hline 19 & Brake pedal adjustment & 5 \\
\hline 20 & Jerks when braking & 1 \\
\hline 21 & Loosening of the brake disc to the front wheel hub & 8 \\
\hline 22 & Caliper (left/right) & 20 \\
\hline & & 339 \\
\hline
\end{tabular}

The greatest number of breakdowns are caused because the front and rear wheels cannot be released or the brakes do not work. Possible causes are brake valve and actuator 
failures, acceleration valve failure, seal failure in the energy accumulator, compressed air leakage, brake spring breakage, brake camshaft jams.

The avoidance of brake system repairs is only possible with timely and good-quality maintenance. The manufacturer's service book [3] defines the mileage for maintenance intervals before MO1 is $10.000 \mathrm{~km}$ and before MO 2 is $20.000 \mathrm{~km}$. The maintenance of the brake system includes the following operations: during MO1visual inspection and instrument readings check the serviceability and tightness of components and pipelines of the brake system in four parameters, checking the condition and fixation of brake mechanisms and cameras, checking the wear of brake pads; during MO2 inspection the operation and adjustment of the service brake, parking brake and auxiliary brake.

Table 2. Nature of suspension malfunction

\begin{tabular}{|c|l|c|}
\hline $\begin{array}{c}\text { № } \\
\Pi / \Pi\end{array}$ & \multicolumn{1}{|c|}{ Nature of suspension malfunction } & $\begin{array}{c}\text { The number of } \\
\text { the removals }\end{array}$ \\
\hline 1 & Knocking in the front axis suspension & 113 \\
\hline 2 & Knocking in the wheel & 53 \\
\hline 3 & Shock absorber replacement & 42 \\
\hline 4 & Unfastening of the front wheel hub & 12 \\
\hline 5 & Pivot axle play & 11 \\
\hline 6 & Misalignment of wheels & 11 \\
\hline 7 & Torsion breakage & 9 \\
\hline 8 & Broken stabiliser bar & 4 \\
\hline 9 & Knocking in the rear axle suspension & 4 \\
\hline 10 & Protective cover of the right pivot axle is pressed out & 1 \\
\hline 11 & Brokenspring tie boltof the front axle & 1 \\
\hline \multicolumn{2}{|}{ Total number of removals } & 261 \\
\hline
\end{tabular}

The greatest number of removalsare caused by knocking in the front axis suspension, knocking in the wheels, replacement of shock absorbers, unfastening of the front wheel hub, pivot axle play, misalignment of wheels.

At MO1 the condition and air tightness of pneumatic cylinders of the bus suspension, condition of attachment of heads to tubes of rear and front suspension torque rods, condition of shock absorbers and their attachment elements are checked. At MO2 the bearing play of wheel hubs and the condition of pivot connections are checked. Maintenance in the bus depotis carried out on time. If the suspension is serviced on time, there should be no removals with repairs.

The analysis of the removals repairs of the suspension and brake system determined that the maintenance is performed in complete volume. The scheduled maintenance service provides for the operation of the vehicles without additional removals between MO 1 and MO 2.

In order to find out the causes of brake and suspension repairs, the performance characteristics are determined quantitatively and the influence of operational factors on the buses.

In addition, operational factors such as sudden braking and accelerating can have an influence on the number of removals with brake and suspension repairs.

\subsection{Research method choice}

To provide the performance of vehiclesand the maintenance of components and assemblies in technically sound state, it is necessary to know the laws governing the changes in the 
technical state of vehicles under the influence of various factors during operation. In other words, vehicle performance management consists in effective application of scientifically grounded methods and standards for maintaining vehicles in technically sound state [4].

Determining the quantitative characteristics of the performance of components and parts of rolling stock is possible with the help of mathematical methods based on the generalization of the accumulated statistical data on their work in real operating conditions. For the development of recommendations for the rational technical operation, improvement of the design of cars, information about regularity of changes in their technical condition is needed. The most important regularities of technical operation include: changes in the technical condition of a vehicle, component, or parts by operating time (running time or mileage); the dispersion of the parameters of the technical state and other random variables that operate the technical operation, for example, the duration of the repair and maintenance work; the formation of the total flow of failures in vehicles (recovery process) [5].

To determine the performance of the braking system and the suspension of the buses, a systematisation of removals was carried out. On the basis of many researches, it has been established that the resource of vehicles, as well as components and parts, under the correct operation, obeys the law of normal distribution.

"Operation of motor vehicles" chair of Volzhsky Polytechnic Institute constantly analyzes the performance of buses "Volzhanin", which consists in evaluation of removals with repair of components and parts with the determination of mileage from the moment of repair to the subsequent removal with repair. At the MUE "Volzhskaya №1732 bus depot" enterprise, there is an automated " $1 \mathrm{C}$ : Enterprise 8. Motor Vehicle Management Standard" program, which allows you to receive statistical data on removals with repair and to determine mileage before the next removal.

The plan for the collection of operating data provides the definition of buses removals with repair of engine, clutch and gearbox with the calculation of mileage to removal with repair.

Evaluation of the parameters of the vehicle mileage distribution to removal with the components repair, performed according to the method of Gmurman V.E., presented in [6].

The source data for calculating the number of objects of observation $\mathrm{N}$ :

The following indicators are used:

- confidence probability

- marginal relative error

- the coefficient of variation

$$
\begin{aligned}
\mathrm{q} & =0,95 ; \\
\mathrm{E} & =0,05 ; \\
v & =0,20 .
\end{aligned}
$$

With these values, the size of selection should be at least 45 .

The coefficient of variation is equal:

with normal distribution (Gaussian)

with Weibull distribution

with exponential distribution

$$
\begin{aligned}
& v=\text { to } 0,3 ; \\
& v=\text { from } 0,3 \text { to } 0,9 ; \\
& v=\text { from } 0,9 \text { to } 1,1 .
\end{aligned}
$$

The calculation is performed according to the following formulas [6]:

arithmetic mean $\bar{x}: \quad \bar{x}=\frac{1}{n} \cdot \sum_{i=1}^{k} x_{i} \cdot n_{i}$,

standard deviation $\sigma$ :

$$
\sigma=\sqrt{\frac{1}{n} \cdot \sum_{i=1}^{k}\left(x_{i}-\bar{x}\right)^{2} \cdot n_{i}}
$$

the coefficient of variation $v$ :

$$
V=\frac{\sigma}{\bar{x}}
$$


confidence interval (interval value of mileage): $\quad\left(\bar{x}-\frac{t \cdot \sigma}{\sqrt{n}} ; \quad \bar{x}+\frac{t \cdot \sigma}{\sqrt{n}}\right)$,

wheren - selection size; $t$ - Laplace function argument, $t=1,96$ when $q=0,95$; $\pm \frac{t \cdot \sigma}{\sqrt{n}}-$ measurement error.

Testing the hypothesis about the normal distribution is performed by the Pearson criterion [6].

As a criterion for testing hypothesis random value is taken. $X^{2}:$

$$
x^{2}=\sum \frac{\left(n_{i}-n_{i}^{\prime}\right)^{2}}{n_{i}^{\prime}},
$$

Where $\mathrm{n}_{\mathrm{i}}$ and $\mathrm{n}_{\mathrm{i}}^{\prime}$-are an empirical and theoretical frequencies.

The area of acceptance of the hypothesis is determined by the inequality:

$$
x^{2}\left\langle x_{k p}^{2} \quad(\alpha ; k)\right.
$$

where $\alpha$ - level of statistical significance, $k$ - number of degrees of freedom.

The level of significance $\alpha$ in the calculations is $\alpha=0,05$. Number of degrees of freedom $k$ defined by equation: $k=s-1-r$,

wheres - number of selection groups; $r$ - the number of parameters of the intended distribution (for normal distribution $r=2$ ), so $k=s-3$.

Rule. In order, at a given level of significance, to test the hypothesis about the distribution of the population according to the normal law, it is necessary to calculate the theoretical frequencies, and then the observed value of the criterion $x^{2}$. According to the table of critical points of the distribution $x^{2}$, given level of significance $\alpha$ and number of degrees of freedom $k=s-3$ find the critical point $x^{2}(\alpha ; k)$. If $x^{2}{ }_{o b s e r v}<x^{2}{ }_{k p}$, then the hypothesis is approved. If $x^{2}{ }_{\text {observ. }}>x^{2}{ }_{k p}$, then the hypothesis is rejected.

\subsection{Analysis of the mileage distribution of buses before removals with brake and suspension repairs}

Analysis of removals with repairs of the braking system of buses was carried out and a distribution of mileage before breakdowns was determined. Determination of quantitative characteristics of brake system performance is carried out according to the given methodology (p. 1.2) on the basis of summarised statistical data about bus mileage before repair of brake system and suspension under real operating conditions.

The buses are operated on routes $1,2 \mathrm{u}$ and 14 in Volzhsky. The performance of the vehicles is determined by the technical characteristics of the bus "Volgabus-5270GH". The use of CNG (methane) engine fuel contributes to improving the environment of Volzhsky.

The parameters of bus mileage before the removal with repairs of the braking system and suspension were calculated using formulae 1-3, and the results are presented in Table 3.According to initial assumptions, the distribution of bus mileage should obey a normal distribution law. The calculations showed that the distribution of mileage with brake system repairs does not follow the normal distribution law and obeys the Weibull law - coefficient of variation $v=0.653$ (10 sample groups with the interval of $10000 \mathrm{~km}$ mileage were selected).The distribution of mileage with the suspensionrepairs does not also follow the normal distribution law and obeys the Weibull law - coefficient of variation $=0.87$ (10 sample groups with the interval of $15000 \mathrm{~km}$ mileage are selected). 
The hypothesis of Normal Law distribution of aggregates was tested, based on Pearson's criteria (Tables 3, 4). The test showed that the mileage distribution with removals does not correspond to the normal law of distribution.

Table 3. Checking the distribution of mileage with breakdowns with brake system repairs using Pearson's criterion

\begin{tabular}{|l|l|l|l|l|l|l|}
\hline $\begin{array}{l}\text { Removals } \\
\text { with brake } \\
\text { system } \\
\text { repairs }\end{array}$ & \multicolumn{5}{|l|}{ Parameters of the mileage distribution } & $\begin{array}{l}\text { Correspondence } \\
\text { to the normal } \\
\text { law }\end{array}$ \\
\cline { 2 - 7 } & $n$ & $\bar{x}$ & $\sigma$ & $v$ & $x_{\text {набл. } / x_{k p}^{2}}^{2}$ & $\begin{array}{l}\text { does not } \\
\text { correspond }\end{array}$ \\
\cline { 2 - 6 } & 339 & 14853 & 9700 & 0,653 & $69,68>15,5$ & \\
\hline
\end{tabular}

Table 4. Checking the distribution of mileage with removals with suspension repair using Pearson's criterion

\begin{tabular}{|l|l|l|l|l|l|l|}
\hline $\begin{array}{l}\text { Removals } \\
\text { with } \\
\text { suspension } \\
\text { repair }\end{array}$ & \multicolumn{4}{|l|}{ Parameters of the mileage distribution } & $\begin{array}{l}\text { Corresponden } \\
\text { ce to the } \\
\text { normal law }\end{array}$ \\
\cline { 2 - 7 } & $n$ & $\bar{x}$ & $\sigma$ & $v$ & $x_{\text {набл. } / x_{k p}^{2}}^{2}$ & $\begin{array}{l}\text { does not } \\
\text { correspond }\end{array}$ \\
\cline { 2 - 6 } & 261 & 40948 & 35775 & 0,87 & $335,45>14,1$ & \\
\hline
\end{tabular}

The graphs of the distribution of observed and theoretical bus mileage before removals with brake system repairs are shown, "Fig. 1", with suspension repairs are shown. "Fig. 2".

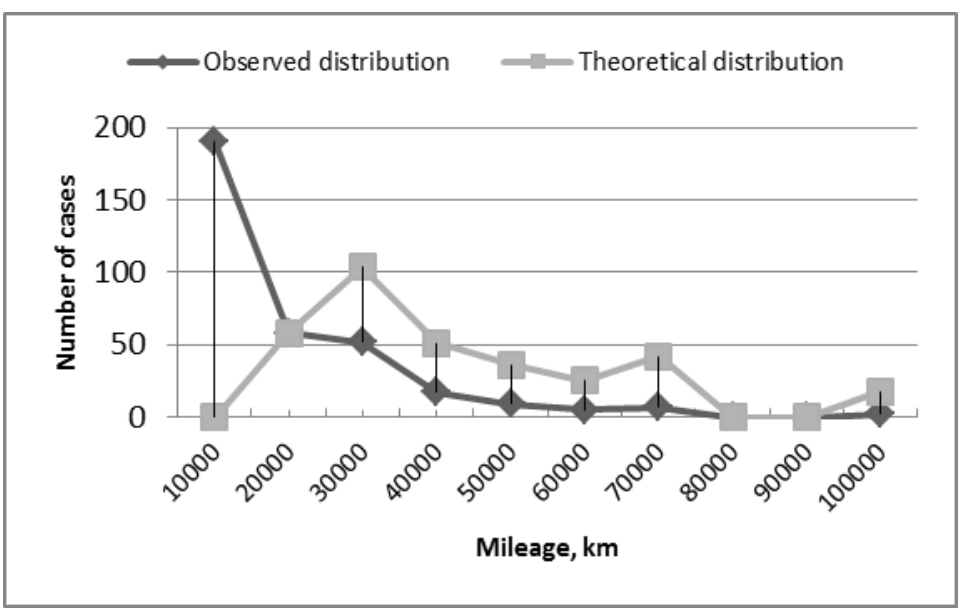

Fig. 1. Distribution graph of bus mileage before removals with brake system repairs 


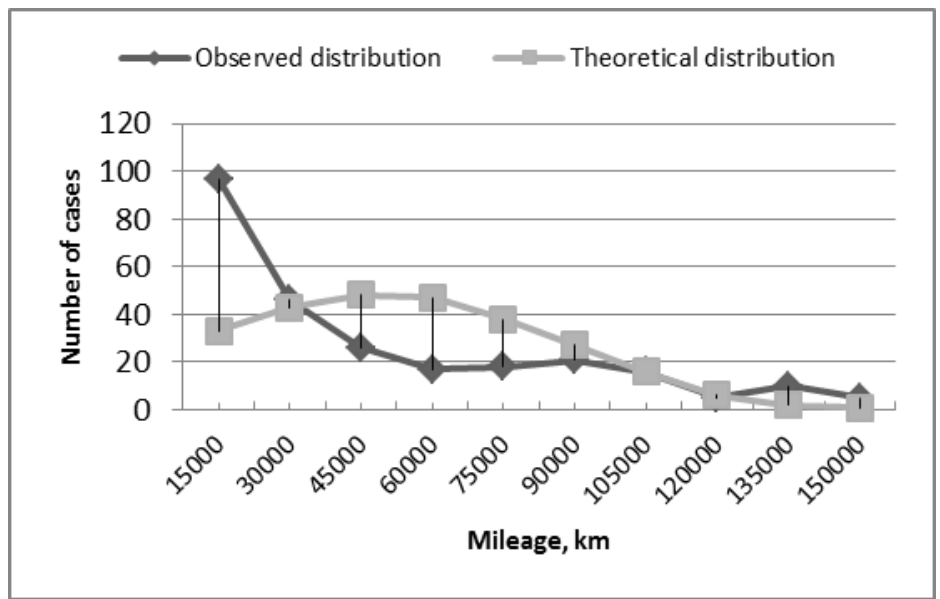

Fig. 2. Graph of the mileage distribution of buses before removalswith suspension repairs

The distributions of observed mileages of removals with brake and suspension repairs (Table 1, Table 2), "Fig. 1", "Fig. 2" obey the exponential law, and the theoretical distributions obey the Weibull law. The maximum number of removals with brake system repairs is 200 out of 339 occurring between 0 and $10,000 \mathrm{~km}$. The maximum number of removals with suspension repairs is 100 out of 261 occurring between 0 and 15,000 km.

The mileage before MO1 is $10,000 \mathrm{~km}$. The highest number of breakdowns occurred before MO 1 and the exponential distribution of bus mileage before breakdowns indicates possible assembly, repair and maintenance irregularities. In addition, premature removals can be influenced by operational factors.

In order to reduce premature removals the mileage before MO1 should be $5,000 \mathrm{~km}$ and before MO2 should be 15,000 km.

Based on [7], forecasting of changes in technical condition and operational properties of bus units and components was carried out using mathematical methods. Using the methodology [8], we assume that removals with repairs have occurred due to the quality of manufacture and assembly of the vehicles and their units, and the run-in conditions. Besides, operating conditions might influence occurrence of malfunctions. Therefore the analysis of influence of operating factors of route network on removals with repair was conducted.

\section{Analysis of Operating Factors Influencing the Clutch Performance}

\subsection{Operational factors affecting bus performance}

Factors affecting the performance of buses are divided into external and internal factors. Internal factors include the operating characteristics of the bus; external factors include operating conditions and maintenance.

This paper considers the effects of operating conditions which, on urban routes, are characterised by high traffic flows, reduced speed, increased engine speeds, high mileage on curved trajectories, high number of gearshifts and which can lead to a reduction in the service life of bus assemblies and components.

The main operating conditions can include road conditions, traffic conditions, driving mode, maintenance and driver qualifications. 
Road conditions on the routes №1, №2u and №14 of Volzhsky are satisfactory. Asphalt surface determines the normal mode of operation of buses and the elimination of cases of buses removals with repair.

Traffic conditions for public transport in Volzhsky are unsatisfactory. The load of the road network occurs due to the large motorization of citizens and a large number of routed taxicabs passing through the same streets as the buses routes. This can affect the decrease in buses speed, the frequency of maneuvering before bus stops, frequent gear changes, the increase friction of brake mechanisms, the frequency of maneuvering in front of the bus stops, and an increase value of bus removals with malfunctions of engine, clutch, gearbox, brake and steering andsuspension systems.

Driving mode of the bus is to be set by the driver, depending on the road conditions, his qualification and the technical condition of the vehicle. The higher the driver's qualifications, the better the buses will perform, the fewer failures there will be, and the longer the buses will run at their best. The municipal bus depot MUE "Volzhskaya №1732 bus depot" employs appropriately qualified drivers. Due to the difficult traffic conditions on the routes, drivers constantly have to consider the influence of operational factors on the technical condition of the buses.

Maintenance. During the warranty period from 2017 to 2019, the buses were under warranty service of Volgabus-Volzhsky Ltd. Since the beginning of 2019, maintenance and repairs have been carried out by thebus depot.

\subsection{Analysis of traffic modes on urban routes}

In order to identify the suspected causes of faults of assemblies and units, an analysis of bus traffic modes on routes №1, №2u, and №14 has been conducted. The study was conducted on weekdays during rush hours at the time of highest traffic flows "Fig. 3,4,5". A smartphone app for measuring vehicle speed and distance travelled, "SpeedView: GPSSpeedometer", was used for the study. The percentage of running time of buses was determined during even driving, during acceleration and in deceleration mode. [9]

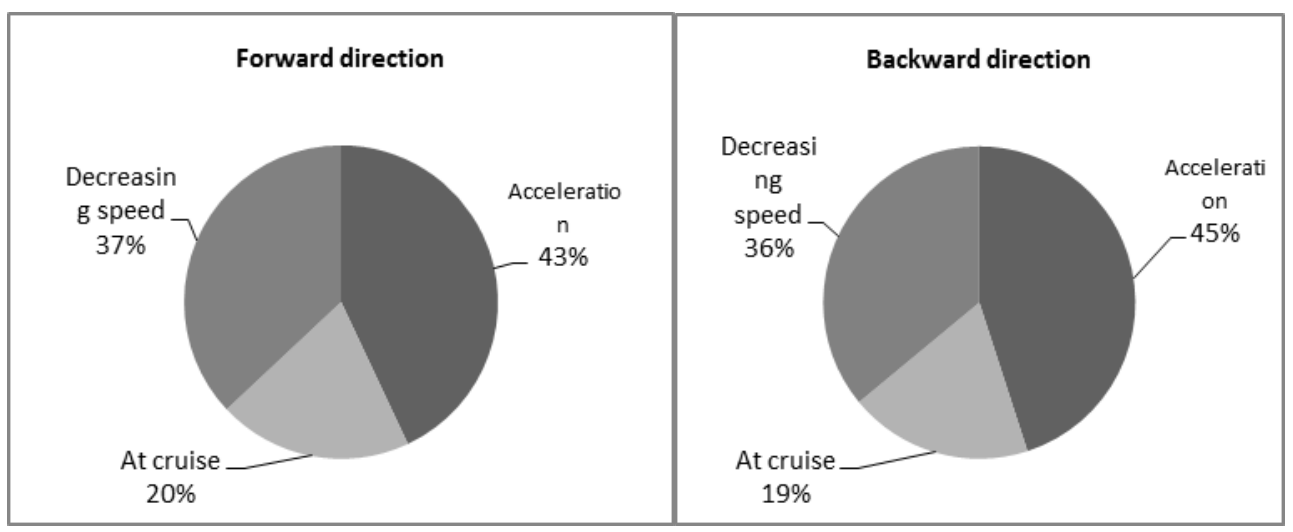

Fig. 3. Bus modes on route№ 1 in forward and backward directions 


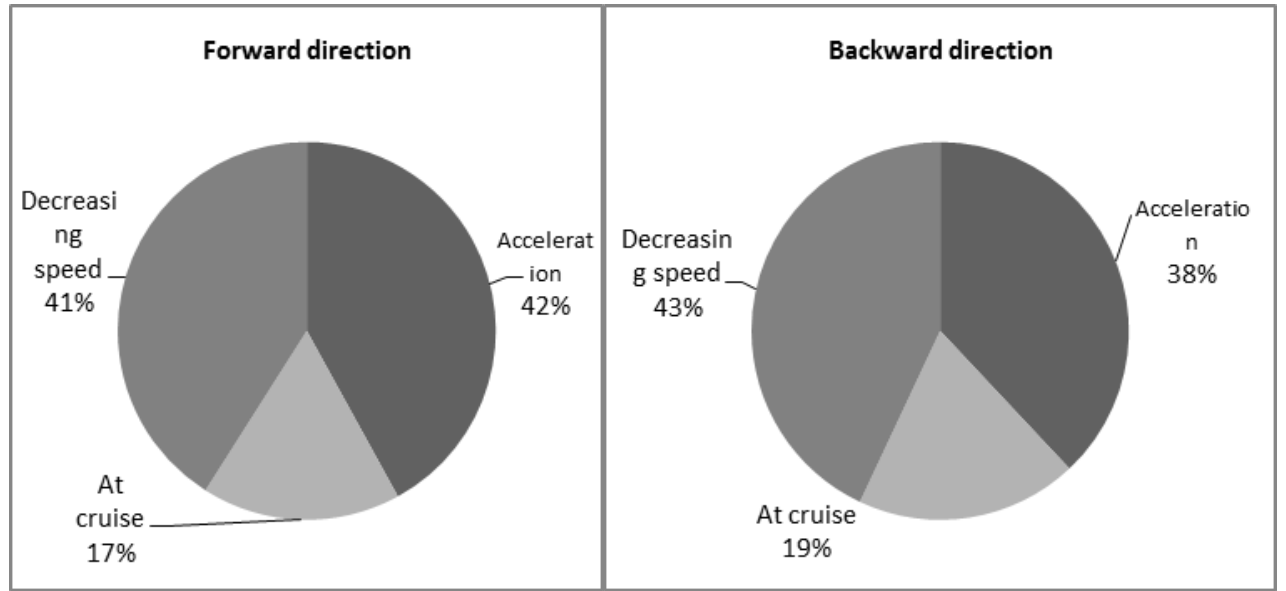

Fig. 4. Bus modes on route №2u in forward and backward directions

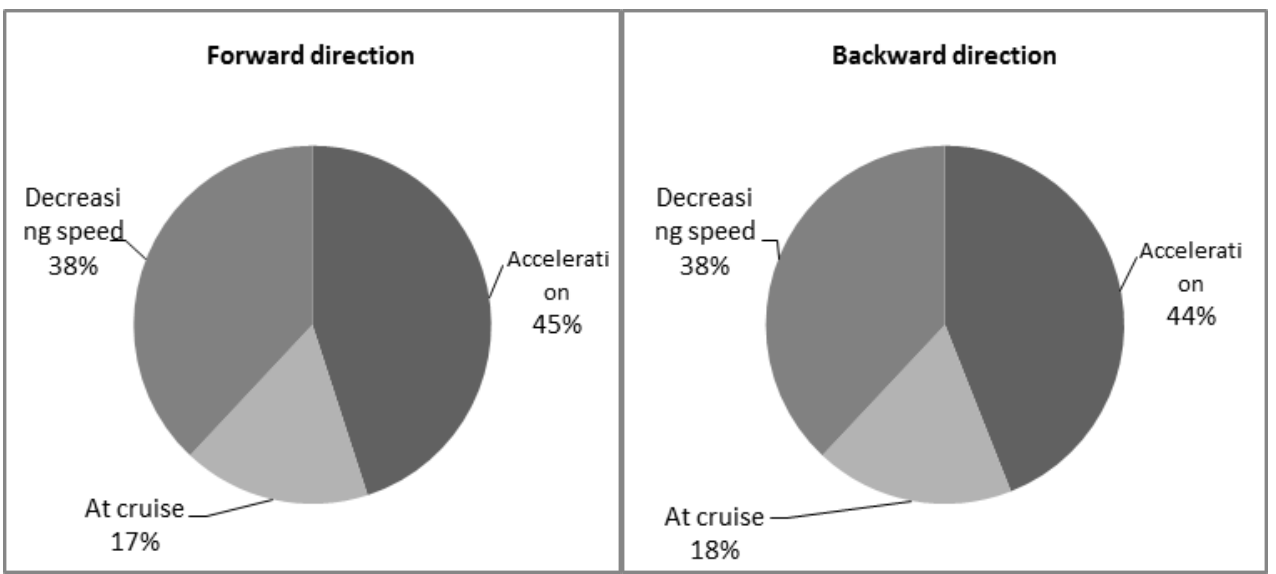

Fig. 5. Bus modes on route №14 in forward and backward directions

The distribution of the traffic modes is shown in Table 5.

Table 5. Distribution of bus modes on the routes

\begin{tabular}{|c|c|c|c|c|c|c|c|}
\hline \multirow{3}{*}{$\begin{array}{l}\text { № } \\
\Pi / \Pi\end{array}$} & \multirow{3}{*}{ Route no } & \multicolumn{6}{|c|}{ Route no } \\
\hline & & \multicolumn{3}{|c|}{ Forward direction } & \multicolumn{3}{|c|}{ Backward direction } \\
\hline & & №1 & №2У & №14 & №1 & №2y & №14 \\
\hline 1 & $\begin{array}{l}\text { Decreasing } \\
\text { speed }\end{array}$ & 37 & 41 & 38 & 36 & 43 & 38 \\
\hline 2 & Acceleration & 43 & 42 & 45 & 45 & 38 & 44 \\
\hline 3 & At cruise & 20 & 17 & 17 & 19 & 19 & 18 \\
\hline
\end{tabular}

As it can be seen from diagrams "Fig. 3, 4, 5", (Table 5), buses of routes №1, №2u, and №14 in urban conditions operate in variable mode with frequent acceleration and deceleration, with frequent changes in road resistance and traffic conditions, which is most typical for intensive urban traffic. The even running of buses is 17 to $19 \%$, the rest of the time the bus runs in deceleration and acceleration modes. Varying vehicle operation disturbs the thermal and frictional stability of the vehicle's components and systems. It 
increases the intensity of the wear rate of units and components andit increases fuel consumption. [10]

Due to the high frequency of acceleration and deceleration, the vehicle experiences sinusoidal loads of completely different magnitudes, which can be one of the causes of frequent removals with faulty brakes and suspension.

\section{Findings}

1. The maximum number of removals with brake system repairs is 200 out of 339 occurring between 0 and $10,000 \mathrm{~km}$. The maximum number of breakdowns with suspension repairs is 100 out of 261 occurring between 0 and $15000 \mathrm{~km}$.

2. Mileage before MO1 is $10,000 \mathrm{~km}$, mileage before MO2 is 20,000 km. That is, repairs occur before the next MO should be carried out.

3. The analysis of operational factors on the route network of Volzhsky has shown that premature derailment of buses with repairs is possible due to traffic conditions and traffic modes: high traffic flow, delays and maneuvering in front of traffic lights and pedestrian crossings, delays and maneuvering in front of a bus stop due to waiting for a free space.

4. All the factors considered lead to a constant change in driving speed, an increase in engine speed, wear of brake linings, a large run during a curvilinear trajectory of movement, a large number of gear changes. In the components and in the engine, the stability of the thermal regime and friction is disturbed.

\section{Suggestions}

1. In order to reduce premature removals, the mileage before MO1 should be reduced from $10000 \mathrm{~km}$ to $5000 \mathrm{~km}$, and before MO2 from $20000 \mathrm{~km}$ to $15000 \mathrm{~km}$.

2. To improve the performance of buses, the impact of operational factors on the route network needs to be reduced.

3. Reduction of traffic flow is possible through redistribution of transit vehicles to other streets, allocation of a separate lane for public transport, increase of stop lengths and allocation of separate places for medium and large capacity buses ofthe municipal bus depot MUE "Volzhskaya №1732 bus depot” to eliminate maneuvering.

Authors are grateful to the specialists of the municipal unitary enterprise «Volzhskaya №1732 bus depot» for the opportunity to use buses removals statistical materials.

\section{References}

1. Chernova G.A., Vatolin D.I. Providing serviceability of bus suspension "VOLGABUS-5270GH" with choice of diagnostic stand // Student Bulletin: electron. scientific journal. $2020 . \quad$ № 21(119). URL: https://studvestnik.ru/journal/stud/herald/119.

2. Chernova G.A. Konoshenko V.E. Application of mathematical methods for estimation of braking system of buses "Volgabus-5270GH" // Student Bulletin: electronic scientific journal. № 22 (120). URL: https://studvestnik.ru/journal/stud/herald/120

3. Vehicle log book.Bus Volgabus 5270GN-0000010 (gas). OOO VOLGABUS. 2017.

4. Atapin V G Fundamentals of technical systems performance. Automotive transport. Novosibirsk: NSTU publisher, 2006. - 192 p. 
5. Isaenko P V Fundamentals of technical systems performance: in 2 parts: Tomsk: TSUAB publisher, 2014. - $324 \mathrm{p}$.

6. Gmurman V E Probability Theory and Mathematical Statistics: Tutorial for universities - 9th ed.: 2003.- $479 \mathrm{p}$.

7. Kulko P.A. Alternative forecasting of changes in the technical condition and operational properties of cars: Monograph. Volgograd: VolgSTU, 2011. - 187 p.

8. Abaimov R V, Malaschuk P A Fundamentals of technical systems performance. Syk. forestuniv.- ed. second, revised. - Syktyvkar: SFU0, 2007. - 92 p.

9. Popov A.V., Chernova G.A. Operational conditions and driver's work stress: monograph / A.V. Popov, G.A. Chernova. Ministry of Science and Higher Education of Russian Federation, VPI (branch) FSBEI of Higher Education VolgSTU. Volgograd :VolgSTU Publishing House, 2021. - 347 p

10. Zorin V.A. Fundamentals of performance of technical systems: textbook for students of higher educational institutions. Moscow: Publishing Centre "Academia", 2009. $208 \mathrm{p}$. 